\title{
Using the Participatory Action Research Involved in Concept of the SEP for Developing Fabric of Karen Wisdom in Kanchanaburi Border Patrol Police School
}

\author{
Supaluk Satpretpry, Pornchai Nookaew and Khwanchai Praditsin
}

\begin{abstract}
The purpose of this research was to using the participatory action research involved in concept of the Sufficiency Economy Philosophy (SEP) for developing fabric of Karen wisdom for the Royal initiatives in Kanchanaburi Border Patrol Police schools and cultural and security implications of students. Population were 11 border patrol schools in Kanchanaburi. Samples were by simple random sampling. The experiment groups were Sundaravej and Mitmonchon 2 Border Patrol Police schools, control group was Tilipa Border Patrol Police School.
\end{abstract}

Research methodology was based on 4 steps of participatory action research, basic information survey, planning, experiment and evaluation and summary.

The instruments used consisted of 1) Fabric of Karen Wisdom Test 2) The performance of Fabric of Karen Wisdom Test 3) Cultural assessment 4) Security assessment and 5) In-depth interview. Data analysis were mean, standard deviation, comparison between experiment and control group and content analysis. Found that:

1. Mean of Fabrics of Karen wisdom after experiment between experimental group and control group was statistically significant difference at 0.05 level.

2. Cultural assessment. Overall found that all average were at high levels. That was based on the research hypothesis.

3. The security assessment revealed that total average score was at moderate level.

Index Terms-Border patrol police school, fabric of karen wisdom, participatory action research, sufficiency economy philosophy.

\section{INTRODUCTION}

According to the National Education Act, BE 2542 and Amendments (No.2) BE2545 Aptitude [1] It was necessary to encourage students to learn from their real experiences by integrating their knowledge in a balanced way, to make learning happen all time and all places. Basic education must provide a variety of activities, cooperate with all relevant

Manuscript received April 5, 2018; revised August 30, 2018. The research program for using the Participatory Action Research Involved in Concept of the Sufficiency Economy Philosophy for Developing Fabric of Karen Wisdom for the Royal Initiatives in Kanchanaburi Border Patrol Police school was funded by Kanchanaburi Rajabhat University, Thailand. Budget fiscal year 2017.

Supaluk Satpretpry and Pornchai Nookaew are with Faculty of Education, Kanchanaburi Rajabhat University, Thailand (e-mail: ssuprarak@yahoo.com, sup.satpretpry@gmail.com).

Khwanchai Praditsin is with Sundaravej Border Patrol Police School, Kanchanaburi Province, Thailand (e-mail: mee_rak_khwan@hotmail.com). agencies and resource mobilization for education.

Participatory action research was techniques to change from top-down to bottom-up. The person who was researcher must changed the role of passive to an active or participants or research on them were by them and for them [2]. They were involved in all stages of research, It was both the decision maker, the practitioner and the person affected by the action. In addition, the nature of participatory action research, the role of the researcher had also changed, as a specialist, he became an equal research participant.

The Sufficiency Economy Philosophy (SEP) was used as a part to develop the society. It was found that the school needs to apply the sufficiency economy philosophy as part of the learning activities. The school want to work together with Kanchanaburi Rajabhat University which the experience of applying sufficiency economy philosophy.

Local woven fabrics are geographically connected, settlement of races, as well as traditional beliefs are elements, and the material selection, design patterns and colors of woven fabrics to determine the type of fabric, to use in accordance with the basis of living in each group. Karen cloth is a famous folk handicraft of Karen people in Kanchanaburi. There was a unique feature in the weaving process that was different from other woven fabrics, that was straight leg forward both sides. The strap was attached to the waist called that "waist loom", which is the back strap, which is a pattern inspired by nature. [3] It was also related to the costume culture of Karen women.

From the Thai society Karen Kanchanaburi today found that weaving Karen has decreased. Later generations did not know Karen weaving. If we use Karen cloth for rites or occasions, we have to buy Karen from other sources, the color of the pattern was not the Karen cloth of Kanchanaburi, to Impact on cultural identity of the Karen people. The value of the use of Karen textiles has changed due to economic, social, technological and material values that making traditional handicrafts not popular. Karen people lack of appreciation of the cultural values of ethnic identity.

The results of the study concluded that, Basic Education, Particularly the Border Patrol Police School wanted to bring Sufficiency Economy Philosophy as a part of learning, there is no application of local wisdom weaving Karen. Nowadays, people are interested in Karen Fabric very little. Therefore, the researcher is interested in introducing the concept which is the essence of Sufficiency Economy Philosophy, including the basic education mission, main tasks of higher education institutions, Participatory Action Research to use in the development of local wisdom of Karen Fabric of the Border Patrol Police School in Kanchanaburi province. 


\section{RESEARCH OBJECTIVES}

1) To study the effect of using participatory action research process involved in concept of the Sufficiency Economy Philosophy for developing Fabric of Karen Wisdom for the Royal initiatives in Kanchanaburi Border Patrol Police schools.

2) To study the effect of culture and security on participatory action research process involved in concept of the Sufficiency Economy Philosophy for developing Fabric of Karen Wisdom for the Royal initiatives in Kanchanaburi Border Patrol Police schools.

\section{RESEARCHER HYPHOTHRSIS}

1) Participatory Action Research and the philosophy of sufficiency economy should developed the fabric of Karen Wisdom of Kanchanaburi Border Patrol Police School of students better.

2) Participatory Action Research and the philosophy of sufficiency economy developed better culture and security of student.

\section{RESEARCH METHODOLOGY}

Population and sample. Population is 4-6 students from 11 Kanchanaburi Border Patrol Police Schools. Sample were 4-6 grade students from 3 Border Patrol Police Schools. Random sampling using simple random sampling. The experimental groups were Sundaravej Border Patrol Police schools, of Mitmonchon 2 Border Patrol Police schools, the control group was Tilipa Border Patrol Police schools.

The procedure was based on 4 steps of participatory action research.

Step 1: The basic information survey consists of 3 activities: the study of Karen weaving techniques from local wisdom. Study relevant documents and focus groups to teacher and community members who are local wisdom. Found that basic information about Karen weaving of the community of Sanagphong District in area of Suntaravej Border Patrol Police School and the community of Khao Jot in Mitmonchon 2 Border Patrol Police School. A group discussion was conducted to identify the activities of the Royal Initiative Project and to express opinions on the application of the philosophy of sufficiency economy to the development of Fabric of Karen Wisdom. The researcher conclusion basic information, check the consistency of basic information.

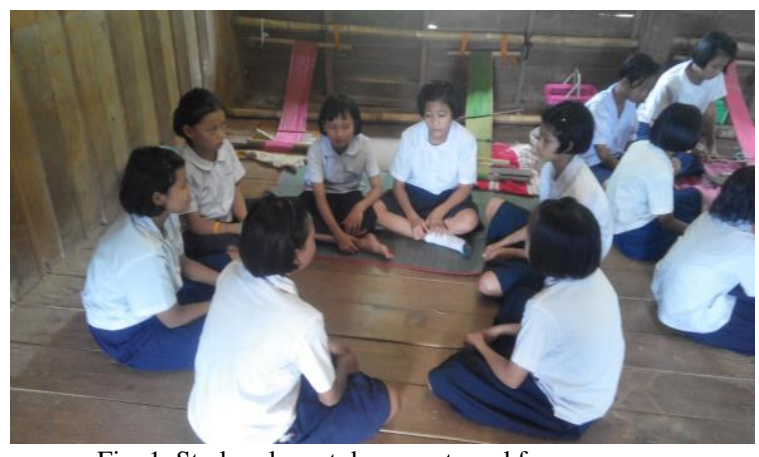

Fig. 1. Study relevant documents and focus groups.
Step 2: Planning. Researcher planed from conclusion basic information in Step 1 about Fabric of Karen Wisdom and philosophy of sufficiency economy. Researcher planed 2 topic, Topic 1 planned to curriculum development in 4 step. There were (1) basic information survey; (2) curriculum development; (3) curriculum try out; (4) evaluation and curriculum improvement. Topic 2 Researcher planned to develop instruments. The instruments were (1) Fabric of Karen Wisdom Test; (2) The performance of Fabric of Karen Wisdom Test; (3) Cultural Assessment; (4) Security Assessment; 5) In- depth interview.

Step 3: The experiment. Researcher used curriculum of "using participatory action research process involved in concept of the Sufficiency Economy Philosophy for developing Fabric of Karen Wisdom for the Royal initiatives in Kanchanaburi Border Patrol Police schools" in the first semester of B.E. 2560. The experiment group were students at Suntaravej Border Patrol Police School and students at Mitmonchon 2 Border Patrol Police School. According to the implementation of the Royal Initiative was a vocational training program. The activities according to the lesson plan were 4 step as follows: Step 1 survey, Step 2 planning as in Fig. 1, Step 3 activity in classroom as in Fig. 2 and Step 4 conclude.

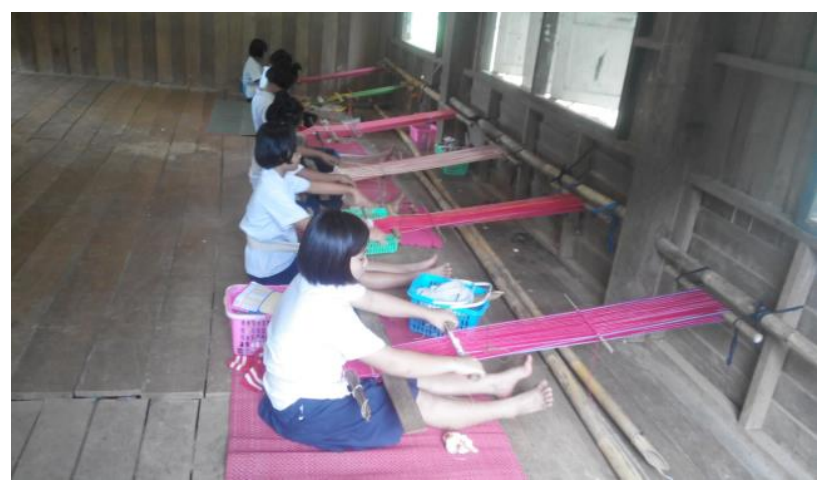

Fig. 2. Fabric of Karen activities

Step 4: Evaluate and summarize 4 topics: 1) Using the participatory action research process involved in concept of the Sufficiency Economy Philosophy for developing Fabric of Karen Wisdom for the Royal initiatives in Kanchanaburi Border Patrol Police schools 2) cultural assessment, 3) security assessment and 4) in-depth interview. The focus is on participating in Border Patrol Police Schools at all step as in Fig. 3.

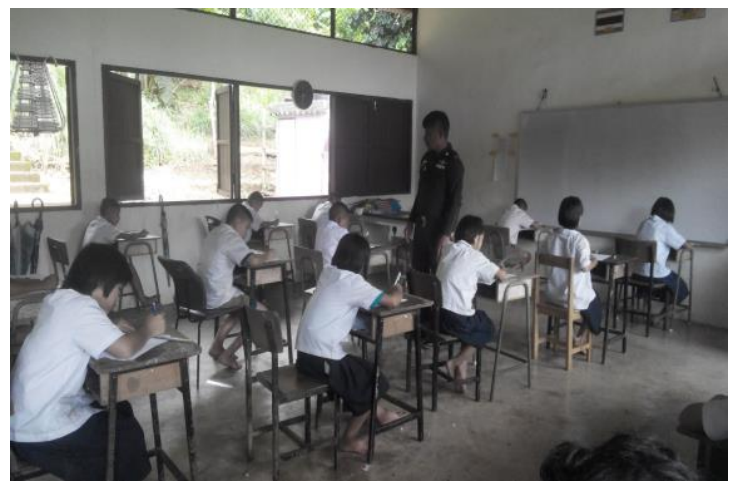

Fig. 3. Fabric of Karen Fabric of Karen, cultural and security assessment.

The 4 steps of this research were as Fig. 4 . 


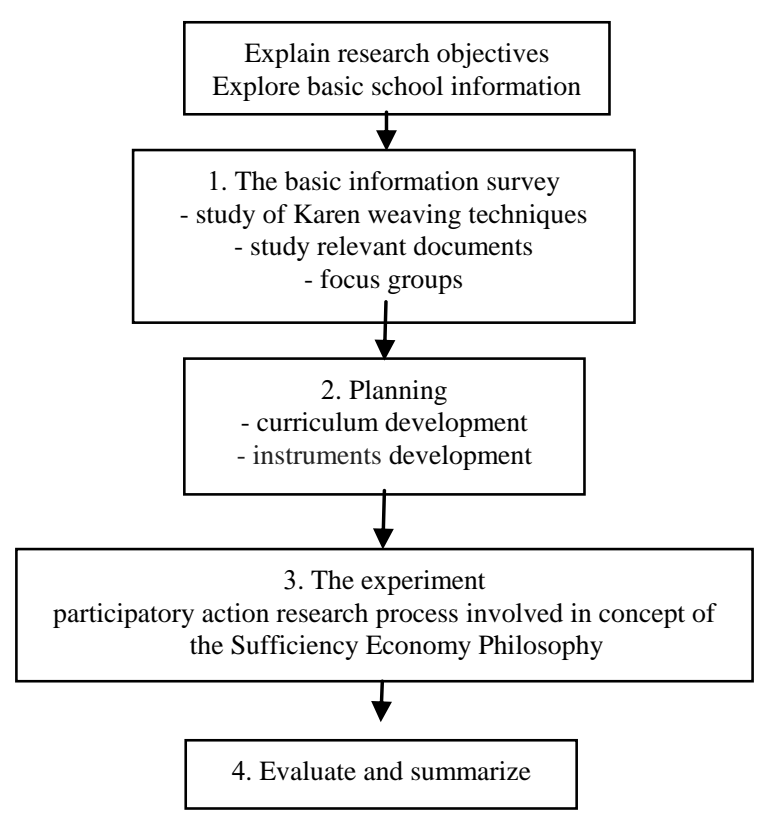

Fig. 4. Research proceed on 4 steps.

\section{CONCLUSION}

The research results are presented as follows.

1) Using the participatory action research involved in concept of the Sufficiency Economy Philosophy for developing Fabric of Karen Wisdom for the Royal initiatives in Kanchanaburi Border Patrol Police schools based on the findings of subsection 5.1.1-5.1.7.

a) Comparison of the mean of Fabric of Karen Wisdom before the experiment between Sundaravej Border Patrol Police Schools and Mitmonchon 2 Border Patrol Police schools, an experiment group and Tilipa Border Patrol Police schools, a control group, was no difference statistically significant at the .05 level.

b) Comparison of the mean of Fabric of Karen Wisdom of multiple comparison test after the experiment between Sundaravej Border Patrol Police Schools and Mitmonchon 2 Border Patrol Police schools, an experiment group and Tilipa Border Patrol Police schools, a control group, was difference statistically significant at the .05 level as in Table I.

TABLE I: COMPARE MEAN OF FABRIC AFTER EXPERIMENT

\begin{tabular}{lccccc}
\hline \multicolumn{1}{c}{ SV } & SS & df & MS & F & Sig. \\
\hline Between group & 72.11 & 2 & 36.05 & 11.87 & 0.00 \\
Within group & 221.68 & 73 & 3.04 & & \\
Total & 293.79 & 75 & & & \\
\hline \hline
\end{tabular}

c) Comparative study of Fabric of Karen Wisdom was LSD test, after the experiment between Sundaravej Border Patrol Police Schools and Mitmonchon 2 Border Patrol was no difference statistically significant at the .05 level.Comparison of the mean of Fabric of Karen Wisdom was LSD test after the experiment between Sundaravej Border Patrol Police Schools and Mitmonchon 2 Border Patrol Police schools, an experiment group and Tilipa Border Patrol Police schools, a control group, was difference statistically significant at the .05 level as in Table II.

d) Before the experiment, the cognitive average score for Fabric of Karen Wisdom of Sundaravej Border Patrol
Police Schools was 9.97and the standard deviation was 1.18. After the experiment was 12.86 and the standard deviation was 2.18 . Statistically significant at the 0.05 level.

e) Before the experiment, the cognitive average score for Fabric of Karen Wisdom of Mitmonchon 2 Border Patrol Police Schools was 9.69 and the standard deviation was 1.20. After the experiment was 11.88 and the standard deviation was 0.89 . Statistically significant at the 0.05 level.

f) Before the experiment, the cognitive average score for Fabric of Karen Wisdom of Tilipa Border Patrol Police Schools was 9.38 and the standard deviation was 1.21. After the experiment was 10.63 and the standard deviation was 1.38 . Statistically significant at the 0.05 level.

g) The results of performance of Fabric of Karen Wisdom in the whole group showed that the mean scores were very good. This was better than the criteria set.

TABLE II: MULTIPLE COMPARISON TEST

\begin{tabular}{lccc}
\hline \hline \multicolumn{2}{c}{ compared school } & Means different & Sig \\
\hline Sundaravej & Mitmonchon 2 & 0.99 & 0.06 \\
Mitmonchon 2 & Tilipa & $1.25^{*}$ & 0.03 \\
Sundaravej & Tilipa & 2.24 & 0.00 \\
\hline \hline
\end{tabular}

*.05 sig

The cultural assessment as a whole found that there are average values on all levels. This was better than the criteria set.

2) The overall security assessment was moderate. This is consistent with the criteria set.

3) in-depth interviews summary:

a) Using the participatory action research process involved in concept of the Sufficiency Economy Philosophy for developing Fabric of Karen Wisdom for the Royal initiatives in Kanchanaburi Border Patrol Police schools. It was found that teachers, parents and students were very involved. From the study of the needs of the school in the use of local wisdom applied to Fabric of Karen Wisdom. Teachers and peer educators, as well as researchers, play a role in helping to develop curriculum. The wisdom of the villagers helped teach the students how to weave the patterns Fabric of Karen Wisdom.

b) Cultural Effects from Using the participatory action research process involved in concept of the Sufficiency Economy Philosophy for developing Fabric of Karen Wisdom for the Royal initiatives in Kanchanaburi Border Patrol Police schools had a very cultural effect. In the in-dept interview, the parents commented that their children were more aware of the traditional wisdom of Karen weaving. They did not want to use woven cloth when there are important traditions. But when they learned to make cloth they wanted to wear clothes that they wore. They were proud and wanted to preserve the beautiful culture and tradition to continue. Especially Fabric of Karen Wisdom

c) Security Effects from Using the participatory action research process involved in concept of the Sufficiency Economy Philosophy for developing Fabric of Karen 
Wisdom for the Royal initiatives in Kanchanaburi Border Patrol Police schools, found that students and communities were more secure in terms of religion and culture, but also lacked security, safety in life and property, health, education and family. Frequent accidents, Most of the accidents in the workplace was hit by a knife, injured by a sickle, injured by Agricultural tools but there are no medical facilities in the community, or very far away. It was not easy to go hospital.

\section{DISCUSSION}

1) Comparison of mean of local fabrics of Karen wisdom after experiment between experimental group and control group. The experiment was statistically significant difference at the 0.05 level. The comparison between local fabrics of Karen wisdom was found to be statistically significant at 0.05 level. The difference between the experimental group and the control group was statistically significant at the 0.05 level. It was found that the mean of before and after the experiment of 2 school students was statistically significant at the 0.05 level. The founding were accordance with the research hypothesis. That may be due to the participation process from the research team, administrators, teachers, parents and local philosopher. Every department participates actively in all stages of action research. There were 4 steps: Step 1: survey basic information, step 2: planning, step 3: Trying out and step 4: evaluate and summarize. This was in line with the participatory action research to develop the morality of young children, subdistrict Administrative Organization Wanonnoi District Sakon nakonn [4], found that moral behavior of young children after development activities under the project of the development of young children in Buddhist pathways could continuous improve.

And accordance with the study in the ethics and morality of the students followed by the Sufficiency Economy Philosophy of Students: Participatory Action Research, in the case of Pudung Naree School [5] found that students behaved themselves in the moral and ethical aspects of the Sufficiency Economy Philosophy at high level, students needed for moral and ethics development followed by the Sufficiency Economy Philosophy at high level. The results of the evaluation of the moral education project in accordance with the Sufficiency Economy Philosophy of the students were at the highest level. According with the application of the Sufficiency Economy Philosophy to practice of educational institutions in Non Suwan district, Buriram Educational Service Area 3 Office [6] found that the implementation of the Sufficiency Economy Philosophy to practice of the administrators as the whole was at high level. The implementation of the Sufficiency Economy Philosophy to practice of the school teachers. The development of the learners was at high level. The curriculum was further developed by focusing on using of local wisdom as a part of learning activities. In the line with the result of this research.

2) Cultural assessment. Overall found that all average were at high levels. That was better than the criteria setting, especially in 3 aspects: to live simply to make life calm, try to speak Thai correctly and Karen weaving should continue. That was based on the research hypothesis. This may be because after learning about the use of participatory action research methodology applying with the Sufficiency Economy Philosophy to develop local fabrics of Karen wisdom according to the Royal Initiative at Border Patrol Police schools, Kanchanaburi Province. These make students understand the concept, having practice with leaded to self-sufficient and simple living. Sawing that Karen weaving was something should be passed on. Teachers should change teaching methods, let community participated in education, course planning consistent with the way of life of the community. The villagers have knowledge of local fabrics of Karen wisdom then teaching and sharing with students. From the participatory process of teachers, students, and community, using of participatory action research applying the Sufficiency Economy Philosophy to develop local fabrics of Karen wisdom according to the Royal Initiative Project. Border Patrol Police in Kanchanaburi Province made better culture dimension.

This was consistent with the research study on the strategy for development of Karen silk weaving in Ban Kha district, Ratchaburi province [7]. Found that the Karen weaving culture derives from the wisdom of the Karen people who have inherited from the past to current, and still identity weaving traditional of ancient weaving according with patterned design and natural environment color using. In addition with study of the conservation of cultural heritage through the participatory process at Chiang Rak Noi [8] found that the villagers Sala Daeng Nearn were aware of the conservation of religious places and traditions. Consistent with section 4 [9], definition of basic education was: The learning process for the growth of individuals and society, by transferring knowledge, training, cultural continuity, creativity promotes academic progress, creation of knowledge from the environment, society, learning and supporting factors to persons learn continuously throughout life.

3) The security assessment revealed that the total average score was at the moderate level, consistent with the criteria setting. The 2 issues with at the highest level were students in the community live in forest and students went to make merit with parents. That could be seen that security of students in the community was the security in religion and culture and environmental resources dimension which inherited from local wisdom. Including the use of participatory action research and the Sufficiency Economy Philosophy, students were more security. This was in line with the study on ways to promote people's participation in security in Thongphaphum Municipality, Thong Pha Phum District [10], with divides into 3 communities, most of them Buddhists. There were many nationalities, including Thai, Mon, Burmese and Karen. The security problem found were crime, drug and foreign workers

The way to promote people's participation in security of the Thongphaphum Municipality would achieved by all parties to coordinate and create community network [11]. 
The village security consisted of 7 elements, each elements sorted by their importance and weighting were moral and cultural, resources and environment, education and learning, participation of the public, leadership, economic and the effects of narcotic drugs. That was in line with the research that has the highest score in the most important element was the moral, social culture, resources and environment.

\section{SUGGESTION}

1) The participatory action research should be studied in applying the Sufficiency Economy Philosophy to develop local fabrics of Karen wisdom at Border Patrol Police school in Kanchanaburi Province, to strengthen knowledge, the consistent features between the intentions of the Royal initiatives and the National Education Act, BE 2542 (1999) and the Amendments (No. 2) BE 2545or the Basic Education Curriculum BE 2551 or conform to the needs of community and other localities.

2) There should be evaluated research,to study follow-up after the study of participatory action research in application of the Sufficiency Economy Philosophy and developed local fabrics of Karen wisdom at Border Patrol Police school in Kanchanaburi, included studying the factors or obstacles for teachers or administrators in application knowledge to sustainable way working.

3) The next research should be undertaken was development of learning resources for natural resources conservation. Preservation headwaters of the stream, herb plants, sources of knowledge as folk wisdom based on the Sufficiency Economy Philosophy. The emphasis was on participatory action research to build understanding and expand the concept of the Sufficiency Economy Philosophy wider into community.

\section{ACKNOWLEDGMENT}

This research has been completed. It was supported by the Faculty of Education. Kanchanaburi Rajabhat University, Office of the Basic Education Commission, Kanchanaburi Primary Educational Service Area Office 3, and also received scholarships from national budgeting, budget year 2017.

Thank you principal of Suntaravej, Mitmonchon 2 and Tilipa border patrol police schools, along with the teachers, students, fabric of Karen wisdom and parents participating in the research project dedicated to sacrifice, research projects have been completed. Researcher hoped that would have opportunity getting good cooperation likely this case again.

\section{REFERENCES}

[1] Ministry of Education, "National Education Act, BE 2542 (1999) and Amended (No. 2). BE 2545 (2002)," Bangkok: Religious Printing, 1998.

[2] S. Wirot, "Participatory action research: A conceptual framework for research for change and learning," M.S. thesis, Dept. Education Administration, Khonkaen University, p. 54, 2007.

[3] L. Viboon, "Thai fabrics: industrial and social development," Bangkok: Ancient Town, p. 24, 1987.

[4] D. Riantong, "Participatory action research to develop righteousness and ethics for the children, ban pancharoen child development center under tambon Duea Srihanchai Administrative Organization, Amphoe Wanon niwat, Sakon Nakhon," M.S. thesis, Dept. Educational Administration. Sakon Nakhon Rajabhat University, 2011.
[5] U. Phakdee, "Enhancement of students in virtue and moral based upon the philosophy of sufficiency economy through participatory action research: A case of Phadungnaree School under Secondary Educational Service Area office 26," Ph.D. dissertation, Dept. Educational Management, Rajabhat Mahasarakham University, Mahasarakham, Thailand, 2012.

[6] N. Aram, "Applying the philosophy of sufficiency economy to the practice of educational institutions in Non Suwan District Buriram Educational Service Area Office 3," M.Ed., Dept. Educational Management, Buriram Rajabhat University, Buriram, Thailand, 2009.

[7] S. Siriwan, "Strategies for the development of Karen silk weaving in Ban Khae district, Ratchaburi province," M.A. Dept. Development Strategies, Chom Bueng Rajabhat University, Ratchaburi, Thailand, 2008.

[8] T. Ploypattra, "The awareness of cultural heritage conservation through the participation process: A case study of Saladaeng Nua Village, Ching Rak Noi," M.Arch. Dept. Interior Architecture, Bangkok University, Bangkok, Thailand, 2014, pp. 110-125.

[9] Ministry of Education. (1998). National Education Act, BE 2542 (1999) and Amended (No. 3). BE 2545 (2010). [Online]. Available: https://person.mwit.ac.th/01-Statutes/NationalEducation.pdf

[10] S. N. A. Pongphun. "The guidelines for promotion of community participation in security strengthening in Thongphaphum Sub District Muncipality of Thongphaphum district of Kanchanaburi province," M.S. Independent Study, Dept. Local Administration, Khonkaen University., Khonkaen, Thailand, 2010. p. 54

[11] N. Tawee, "Factorial components of village security in central region of Thailand," Ph.D. dissertation, Dept. Management, Christian University, Nakhon Pathom, Thailand, 2010, pp. 124-132.

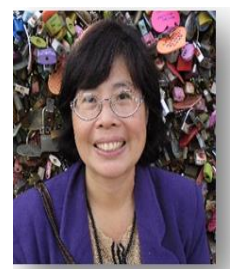

Supaluk Satpretpry was born in Bangkok,Thailand, onJanuary 19, 1960. She got the Ph.D. in behavioral science, Mahatama Gandti University, Kottayum, India. 2002; the M.D. in counselling psychology, Chulalongkorn University, Bangkok, Thailand, 1989; the B.D. in psychology, Thammasat University, Bangkok, Thailand, 1983. She used to be a lecturer in the Faculty of Education Surat Thani Rajabhat University, Surat Thani province. Thailand. Currently, she is a lecturer in the Faculty of Education, Kanchanaburi Rajabhat University, Karnchanaburi province.

Academic performance: A Study of Factors Affecting Success in Graduate Studies Kanchanaburi Rajabhat University. The $13^{\text {th }}$ Conference Materials, National Conference on Education, Moving Forward into the Digital Learning and Teaching Era, SilapaKron University, Nakorn Pratom Province, Thailand, 2017. Current and previous research interests were about Local Study, Participatory Action Research, Counselling Psychology. Assistant Professor Dr. Supaluk Satpretpry. Outstanding researcher award, Asian Institute of Technology, Thailand.

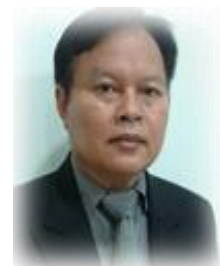

Pornchai Nookaew was born in Khon Kaen, Thailand, on January 11, 1960. He got the Ed.D. in curriculum research and development, Srinakharinwirot University, Bangkok, Thailand 1998; the M.D. in educational measurement, Srinakharinwirot University, Bangkok, Thailand, 1989; the B.D. in mathematics, Srinakharinwirot University, Mahasarakram, Thailand, 1984. He used to be a lecturer in the Faculty of Education Mou Ban Chom Bueng Rajabhat University, Ratchaburi province. Currently, He is a lecturer in the Faculty of Education, Kanchanaburi Rajabhat University, Karnchanaburi province.

Academic performance: Completely Randomized Design. in Journal of Liberal Arts RMUTT. Vol. 1, no. 2. pp. 79-103. July-December 2017. Current and previous research interests were about Educational research, Classroom action research, Computer use in educational evaluation. Associate Professor Dr. Pornchai Nookaew. Outstanding researcher award, Asian Institute of Technology, Thailand.

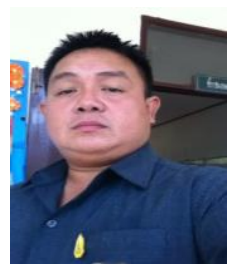

Kuanchai Praditsin was born in Bangkok, Thailand, on October 21, 1974. He got the M.D. in educational research and Evaluation, Kanchanaburi Rajabhat University, Karnchanaburi province, Thailand, 2015; the B.D. in policy, Pratom Thahi University, Pratom Thahi Province, Thailand, 1997. He used to be a teacher in Ban Un Rak, Karnchanaburi province, Thailand. Currently, he is Suntaravej Border Patrol Police School, Kanchanaburi Province, Thailand. His current and previous research interests were about local study, local wisdom education. 